\title{
Relação entre tempo de isquemia e performance pós-operatória no transplante cardíaco
}

Luís Sérgio FRAGOMENI*, Robert S. BONSER**, Ulrich STEMPFLE**, Steves W. RING**, Michael P. KAYE ${ }^{* *}$, Stuart W. JAMIESON**

RBCCV 44205-84

FRAGOMENI, L. S.; BONSER, R. S.; STEMPFLE, U.; RING, S. W.; KAYE, M. P.; JAMIESON, S. W. - Relação entre tempo de isquemia e performance pós-operatória no transplante cardiaco. Rev. Bras. Cir. Cardiovasc., 4(2): 139-142, 1989.

RESUMO: A presente dificuldade na obtençāo de doadores adequados para o transplante cardiaco obriga à necessidade da utilização de órgãos removidos à distância, prolongando, assim, o tempo de isquemia total (TIT). Os efeitos do TIT sobre a função cardiaca no pós-operatório imediato e a necessidade de agentes inotrópicos ainda são controversos, devendo os limites de segurança serem determinados. As manifestaçōes do TIT no índice cardíaco, durante os primeiros três dias pós transplante cardiaco ortotópico (I/C 1-3), o período total do suporte inotrópico (SIT), a dose total/kg de dopamina e dobutamina (D+D/kg), a necessidade inotrópica máxima e picos dos niveis de CPK-MB (CPK-MB) foram medidos em 96 receptores de transplante cardiaco, na Universidade de Minnesota, para determinar a relação destas variáveis com - TIT. O TIT variou entre 61 e 288 minutos (média 171,7, D.P. 51,9). A população foi dividida entre grupos representando intervalos de $\mathbf{3 0}$ minutos. Embora os niveis de CPK-MB fossem inferiores nos grupos de TIT menores, não houve diferença nos parâmetros de funçăo cardiaca, tempo de suporte e necessidade inotrópica. Concluímos que tempos de isquemia até cinco horas são bem tolerados e que outros fatores, como funçăo cardiaca do doador previamente à remoção do órgão, ou possível dano isquêmico durante a remoção, são mais importantes na determinação da performance pós-operatória imediata.

DESCRITORES: transplante cardiaco, humano, isquemia miocárdica; transplante cardiaco, humano, pós-operatório; transplante cardiaco, humano, doadores.

\section{INTRODUÇÃO}

O transplante cardíaco é, hoje, modalidade terapêutica estabelecida e altamente efetiva no tratamento da doença cardiaca em fase final. O registro da Sociedade Internacional de Transplante Cardíaco (ISHT), presentemente, contém mais de 8000 transplantes, realizados em vários centros internacionais. $O$ quinto relatório oficial $^{3}$ relata uma sobrevida de $86,4 \%$ após o primeiro ano e $84 \%$ após o quinto ano do transplante. O sucesso desta terapêutica tem estimulado a realização de um número cada vez maior de transplantes, o que, de certa forma, apressou a necessidade da obtenção de órgãos em localidades distantes. A expansão do raio de ação, no que diz respeito à procura de órgãos, já é, hoje, indispensável e, conforme a ISHT, somente $19,5 \%$ dos doadores de coração encontram-se no mesmo hospital do receptor.

Apesar de aceitarmos períodos isquêmicos do coração ao redor de três ou quatro horas como seguros, ainda existe controvérsia a respeito. Com o intuito de revisarmos a performance pós-operatória do coração transplantado de acordo com o tempo de isquemia a

Trabalho realizado no Minnesota Heart and Lung Institute. Minneapolis, Minnesota, USA.

Apresentado ao 16: Congresso Nacional de Cirurgia Cardiaca. Sảo Paulo, SP, 7 e 8 de abril, 1989.

- Do Minnesota Heart and Lung Institute (Professor convidado).

** Do Minnesota Heart and Lung Institute.

Endereço para separatas: Luis Sérgio Fragomeni. Rua Uruguai, 1555, 4 andar, 99020 Passo Fundo, RS, Brasil. 
FRAGOMENI, L. S.; BONSER, R. S.; STEMPFLE, U.; RING, S. W.; KAYE, M. P.; JAMIESON, S. W. - Relação entre tempo de isquemia e performance pós-operatória no transplante cardiaco. Rev. Bras. Cir. Cardiovasc., 4(2): 139-142, 1989.

que o órgão foi submetido, analisamos, aqui, a experiência da Universidade de Minnesota, com 96 pacientes submetidos a transplante cardiaco ortotópico.

\section{CASUISTICA E MÉTODOS}

Durante o período de janeiro de 1984 a dezembro de 1987, 101 receptores receberam transplantes de coração, na Universidade de Minnesota, USA. Para a realização deste estudo, foram excluídos cinco pacientes. Dois devido a prontuário insuficiente, um por ter recebido transplante heterotópico e outros dois devido a bacteremia per-operatória, com prolongada permanência na unidade de terapia intensiva, associada a falência de múltiplos órgãos.

O estado clínico dos receptores, no momento do transplante, é especificado na Tabela 1. Proteçāo miocárdica foi obtida através de infusão de solução cardioplégica cristalóide ( $1000 \mathrm{ml}$, Stanford cardioplegia) e esfriamento tópico. Para transporte, foram acondicionados em envólucro plástico estéril, imersos em solução de Ringer a $4^{\circ} \mathrm{C}$. Todos os casos transplantados, nesta série, foram ortotópicos e conforme técnica cirúrgica já descrita anteriormente em detalhes ${ }^{4}$. O protocolo de imunossupressão incluiu terapia tríplice com ciclosporina-A, azatioprina e prednisona (Tabela 2).

As variáveis estudadas incluiram o tempo de isquemia do órgão (minutos), o pico da enzima CPK-MB (unidades/dl.), o indice cardiaco $(1 / \mathrm{min} / \mathrm{m} 2)$ no $1 ., 2{ }^{\circ}$ e 3 . dia pós-operatório, doses máximas (microgr $/ \mathrm{kg} / \mathrm{min}$ ) de dopamina, dobutamina, isoproterenol, epinefrina e o período total de suporte inotrópico (horas).

TABELA 1

ESTADO CLINICO NO MOMENTO DO TRANSPLANTE (100 PACIENTES)

N. Mort. precoce \% \% Mort.

\begin{tabular}{lrrr}
\hline Suporte mecánico & 5 & 0 & 0 \\
UTI/inotrópicos & 30 & 1 & 3,3 \\
No hospital & 11 & 1 & 9 \\
Fora do hospital & 54 & 3 & 5,5 \\
\hline TOTAL & 100 & 5 & 5 \\
\hline
\end{tabular}

TABELA 2

PROTOCOLO DE IMUNOSSUPRESSAOO

\begin{tabular}{ll}
\hline Ciclosporina A & $\begin{array}{l}4-6 \mathrm{mg} / \mathrm{kg} \text { V.O. } 2-4 \mathrm{~h} \text { pré-op. } \\
\text { Nivel sangüineo } 175 \pm 25 \mathrm{ng} / \mathrm{ml} \text { pós-op. }\end{array}$ \\
Azatioprina & $2,0-2,5 \mathrm{mg} / \mathrm{kg} / \mathrm{d}$ pré e pós-op. \\
Metilprednisona & $500 \mathrm{mg}$ I.V. qdo. em circulaçăo extracorpórea \\
& $125 \mathrm{mg}$ I.V. $8 / 8 \mathrm{~h}$ durante $24 \mathrm{~h}$ \\
Prednisona & $1,0 \mathrm{mg} / \mathrm{kg} / \mathrm{d}$ V.O. \\
& $0,4 \mathrm{mg} / \mathrm{kg} / \mathrm{d}$ V.O. por 2 semanas \\
& $0,2 \mathrm{mg} / \mathrm{kg} / \mathrm{d}$ V.O. por 1 ano \\
\hline
\end{tabular}

\section{RESULTADOS}

O período isquêmico total dos 96 transplantes aqui avaliados variou entre 61 a 288 minutos (média de $\left.171,7^{\prime}\right)$. A média de suporte inotrópico geral foi de 82,5 horas e são especificados em maior detalhe na Tabela 3.

A Tabela 4 registra estes dados (média), analisados a intervalos de 30 minutos, em relação ao tempo de isquemia do órgão transplantado. O único parâmetro em que houve diferença significativa $(p<0,01)$ de acordo com o tempo de isquemia mais prolongado foi o pico da enzima CPK-MB, onde se registraram niveis inferiores nos tempos de isquemia menores. Em todos os outros parâmetros medidos, não houve diferença com o incremento da isquemia dos órgãos transplantados.

A curva atuarial de sobrevida deste grupo demonstra uma sobrevida de $95 \%$ nos primeiros 12 meses após transplante. Nāo houve óbito na fase per-operatória e a mortalidade, nos primeiros 30 e 90 dias, foi de $1 \%$ e $4 \%$, respectivamente.

\section{DICUSSĀO}

No início da experiência com o transplante cardiaco, era exigido que o doador estivesse sendo operado em sala cirúrgica contígua ao receptor. A evolução dos programas, o maior número de candidatos aceitos para transplante e a escassez de doadores tornaram premente a ampliação da área de referência de doadores. A universidade de Stanford iniciou a procura de órgãos

TABELA 3 SUPORTE INOTRÓPICO (96 PACIENTES)

\begin{tabular}{rl}
\hline$<24 \mathrm{H}$ & 10 pacientes \\
$24-28 \mathrm{~h}$. & 22 \\
$48-72 \mathrm{~h}$. & 16 \\
1 semana & 41 \\
1 semana & 7 \\
\hline
\end{tabular}

\section{TABELA 4}

\begin{tabular}{|c|c|c|c|c|c|c|c|}
\hline TIT (min) & $<90$ & $\begin{array}{r}91- \\
120\end{array}$ & $\begin{array}{l}121- \\
150\end{array}$ & $\begin{array}{l}151- \\
180\end{array}$ & $\begin{array}{l}181- \\
210\end{array}$ & $\begin{array}{l}211- \\
240\end{array}$ & $>240$ \\
\hline $\begin{array}{l}\text { CPK-MB } \\
(\mathrm{U} / \mathrm{L})\end{array}$ & 44,5 & 58,2 & 81,7 & 70,9 & 68,9 & 83,2 & 85,8 \\
\hline SIT (h) & 71,6 & 83,7 & 67,1 & 126,1 & 67,9 & 105,4 & 85,2 \\
\hline $\begin{array}{l}\mathrm{D}+\mathrm{D} / \mathrm{kg} \\
(\mathrm{mcg}) \\
\mathrm{IC} / 1\end{array}$ & 311 & 1270 & 314 & 584 & 185 & 555 & 381 \\
\hline$(\mathrm{L} / \mathrm{min} / \mathrm{m} 2)$ & 3,59 & 4,56 & 4,07 & 4,14 & 4,51 & 4,56 & 3,70 \\
\hline IC/2 & 3,83 & 4,46 & 4,37 & 4,16 & 4,27 & 4,15 & 4,10 \\
\hline IC/3 & 3,73 & 3,96 & 3,51 & 3,52 & 3,78 & 3,66 & 4,00 \\
\hline
\end{tabular}

TIT = tempo de isquemia total; SIT: suporte inotrópico total; D + D: dopamina + dobutamina; IC: índice cardiaco. 
FRAGOMENI, L. S.; BONSER, R. S.; STEMPFLE, U.; RING, S. W.; KAYE, M. P.; JAMIESON, S. W. - Relação entre tempo de isquemia e performance pós-operatória no transplante cardiaco. Rev. Bras. Cir. Cardiovasc., 4(2): 139-142, 1989.

à distância, em 1973, estabelecendo esta rotina durante o ano de 1977. A análise de 39 transplantes realizados nos anos de 1977 e 1978, onde 20 pacientes receberam órgãos de doadores removidos em Stanford e outros 19 em localidades distantes, não houve evidências de alteraçōes significativas na função cardíaca imediata, nas enzimas, nas biopsias, na ocorrência de infecção, rejeição ou mortalidade nos primeiros 90 dias pós-transplante ${ }^{6}$. THOMAS et alii ${ }^{5}$ obtiveram ótima resposta hemodinâmica imediata em 12 situaçōes, nas quais os órgãos foram removidos em distâncias de até $1400 \mathrm{~km}$ e quase quatro horas de isquemia. EMERY et alii ${ }^{2} \mathrm{com}$ pararam a evolução de 62 pacientes transplantados, na Universidade de Arizona, onde 15 doadores eram locais, 23 regionais e 24 distantes (isquemia 30 minutos a 233 minutos, média 128 minutos). Nesta série, mesmo somente três meses pós transplante, havia tendência estatística de menor sobrevida nos pacientes com períodos isquêmicos maiores. Após um ano, a sobrevida foi de $93 \%, 56 \%$ e $61 \%$, respectivamente. O Registro de ISHT ${ }^{3}$ também denota o aumento da mortalidade nos primeiros 30 dias, proporcionalmente ao incremento da isquemia. $\mathrm{Na}$ nossa experiência, a exemplo de outros ${ }^{5,6}$, o maior período de isquemia nāo afetou a performance e a sobrevida pós-operatória imediata ou tardia. O único parâmetro que demonstrou diferença de acordo com maior isquemia foi o pico médio da enzima CPK banda MB.
Isto denota que, apesar de bem tolerável clinicamente, o sofrimento celular parece ser proporcional à isquemia a que o órgão é submetido. Nesta série, períodos de até quatro horas e 48 minutos foram bem tolerados clinicamente. Por outro lado, BILLINGHAN et alii ${ }^{1}$, ao estudarem biopsias de coraçōes removidos localmente e à distância, denotaram a presença de endotélio capilar intacto nos coraçōes locais e dano consistente nos distantes. Biopsias realizadas no período de reperfusão também demonstram lesões ultra-estruturais mais significativas de acordo com o maior período isquêmico.

Realísticamente, podemos concluir que a atividade na área dos transplantes está diretamente relacionada à possibilidade de ampliarmos a disponibilidade de órgãos. A escassez de doadores exige, hoje, a obtenção de órgãos à distância. Períodos isquêmicos longos (ao redor de quatro horas) parecem não afetar o sucesso dos transplantes de coração, mas devemos manter eficiente a comunicação entre os grupos cirúrgicos do doador e receptor, diminuindo, assim, ao máximo os periodos de isquemia. Possivelmente, fatores, como o estado cardiológico prévio à remoção do órgão, associado à proteção miocárdica adequada no momento da remoção e implante, sejam mais importantes na determinação da função pós-operatória do que, simplesmente, o período isquêmico per se.

RBCCV 44205-84

FRAGOMENI, L. S.; BONSER, R. S.; STEMPFLE, U.; RING, S. W.; KAYE, M. P.; JAMIESON, S. W.

- Relationship between ischemic time and post-operative performance in cardiac transplantation.

Rev. Bras. Cir. Cardiovasc., 4(2): 139-142, 1989.

ABSTRACT: The current scarcity of satisfactory human heart transplant donors has led to the use of distant procurement of donor organs with prolonged total ischemic times (TIT). The effect of TIT is controversial and is important that the safe limits of TIT are determined. The effect of increasing TIT on cardiac index during the first 3 operative days $(\mathrm{Cl} / 1-3)$, total period of dopamine and dobutamine $(D+D / K g)$, maximum inotropic requirements and peak CPK-MB levels were assessed in 96 consecutive heart transplant recipients, at the University of Minnesota, to determine the relatiosnhip of these variables to TIT. TIT ranged from 61 to $288 \mathrm{~min}$ (mean $171.7 \mathrm{~min}$ ). The population was divided into groups representing $\mathbf{3 0}$ minutes increments of IT. Although reduced levels of peak CPK-MB were evident in the lower TIT groups, cardiac function, support times and inotrope requirements were not different. We conclude that ischemic times of up to 5 hours are well tolerated and that other factors, such as donor heart function prior to harvest and possible ischemic damage during harvest and implantation, are more important determinants of early post-transplant function.

DESCRIPTORS: heart transplantation, human, myocardial ischemia; heart transplantation, human, postoperative period; heart transplantation, human, donors.

\section{REFERÊNCIAS BIBLIOGRÁFICAS}

1 BILLINGHAN, M. E.; BAUMGARTNER, W. A.; WATSON, D. C.; REITZ, B. A.; MASEK, M. A.; RANEY, A. A.; OYER, P. A.; STINSON, E. B.; SHUMWAY, N. E. Distant heart procurement for human transplantation: ultrastructural studies. Circulation, 62(2, Parte 2): $11-19,1980$.
2 EMERY, R.; CORK, R. C.; LEVINSON, M. M.; RILEY, J. E.; COPELAND, J.; MCALLER, M. J.; COPELANG, J. G. - The cardiac donor: six-year experience. Ann. Thorac. Surg., 41: 356-362, 1986.

3 FRAGOMENI, L. S. \& KAYE, M. P. - The Registry of the International Society of Heart Transplantation: Fifth Official Report - 1988. J. Heart Transpl., 7: 249-253, 1988. 
FRAGOMENI, L. S.; BONSER, R. S.; STEMPFLE, U.; RING, S. W.; KAYE, M. P.; JAMIESON, S. W. - Relação entre tempo de isquemia e performance pós-operatória no transplante cardiaco. Rev. Bras. Cir. Cardiovasc., 4(2): 139-142, 1989.

4 JAMIESON, S. W. - Transplantation. In: DUDLEY, H. \& CARTER, D. C. (eds.). Operative surgery, cardiac surgery: heart transplantation. St. Louis, The C. V. Mosby Company, 1986. p. 584-593.

5. THOMAS, F. T.; SZENTPERY, S. S.; MAMMANA, R. E.; WOLFGANG, T. C.; LOWER, R. R. - Long distance transportation of human hearts for transplantation. Ann. Thorac. Surg., 26: 344-350, 1978.

6 WATSON, D. C.; REITZ, B. A.; BAUMGARTNER, W. A.; RANEY, A. A.; OYER, P. E.; STINSON, E. B.; SHUMWAY, N. E. - Distant heart procurement for transplantation. Surgery, 86: 56-59, 1979.

AGRADECIMENTO: Agredecemos aos colegas Jorge Tadeu Reali e Flávio Korb, por terem auxiliado na revisão deste manuscrito.

\section{Discussão}

DR. NOEDIR STOLF

São Paulo, SP

Nós queremos comprimentar o Dr. Fragomeni e colaboradores, pelo trabalho e pela escolha do tema, que apresenta grande importância. A literatura sobre o assunto é controversa; ao lado de trabalhos que mostram resultados concordantes com aqueles aqui apresentados, existem outros, como os do grupo de Tucson, no Arizona, os do grupo do Dr. English, em Cambridge, e do próprio registro da Sociedade International de Transplante Cardiaco, que mostram que, à medida em que crescem os tempos de isquemia, aumenta a mortalidade e/ou aumentam as necessidades de drogas inotrópicas, liberação enzimática, ou alteraçōes funcionais e morfológicas. A realidade brasileira, em relação à procura de órgãos, é completamente diferente, por uma série de questōes logísticas. Numa avaliação de mais de 90 transplantes, apenas $7,4 \%$ eram coraçōes doadores coletados à distāncia e $7,4 \%$, locais. No Instituto do Coraçāo da Faculdade de Medicina da Universidade de São Paulo, com 50 transplantes, as figuras se repetem; apenas $10 \%$ são de transporte à distância; $74 \%$ tinham tempo de isquemia inferior a 90 minutos, $16 \%$ tinham entre 90-120 minutos e $10 \%$ com tempo superior a 120 minutos. Coincidentemente, o único óbito por falha do enxerto foi do paciente com tempo máximo de isquemia de 4 horas. Nós procuramos avaliar a influência do tempo de isquemia no coração doador. Verificamos que a liberação de CKMB foi maior após 120 minutos, porém, nesses valores, influíram três pacientes: um com falha do enxerto e dois com parada cardíaca, de causa respiratória. O indice cardíaco não guardou relação com o tempo de isquemia. O tempo de uso inotrópico, embora maior após 120 minutos, nāo foi estatisticamente significativo. Finalmente, o desempenho do ventrículo direito, avaliado através da ecocardiografia, não mostou, também, relação com o tempo de isquemia. Eu perguntaria se o Dr. Fragomeni tem informaçōes sobre o estado hemodinâmico pré-operatório e qual sua influência na evolução pós-o- peratória. Perguntaria, também, a que ele atribui índices cardiacos tão altos no período pós-operatório imediato. Em conclusão, nossos dados e nossa casuística limitada com tempos de isquemia menores não permitem uma opinião firme, a literatura é controversa e são necessários estudos como este, para esclarecer o assunto.

\section{DR. CARLOS FIGUEROA \\ Belo Horizonte, $M G$}

Inicialmente, gostaria de agradecer à Comissão Organizadora deste Congresso, pelo honroso convite para comentar o trabalho do Dr. Fragomeni. Como todos sabemos, o transplante de coração é, hoje, aceito como uma terapêutica extremamente eficaz no tratamento da doença cardíaca terminal. No livro recentemente editado pelo nosso mestre, Prof. Zerbini, podemos observar o drama que a equipe médica viveu pela obtençăo do coração do doador. $\mathrm{Na}$ atualidade, ainda vivemos a mesma situação, evidentemente numa proporção maior, já que surgiram vários centros de transplante no nosso país. Quais as razōes dessa dificuldade para a obtenção de doadores? 1) Falta uma nova lei definitiva no nosso país que facilite a obtençāo de órgãos; 2) Apoio financeiro para o programa de transplante de coração é inexistente por parte da Previdência, tanto para as equipes médicas, como para os hospitais. É louvável que a iniciativa de profissionais e instituiçōes privadas que desenvolvem o programa de transplante de coração no Brasil. Como desenvolver a obtenção de órgãos à distância, sem os elevados recursos necessários? 3) A crença religiosa, os costumes e a falta de conscientização do nosso povo dificultam as doaçōes de órgãos. Finalmente, gostaria de parabenizar o Dr. Fragomeni, pela brilhante apresentação deste excelente trabalho, assim como pelos resultados que mostram, de maneira clara e indiscutivel, a viabilidade de obtenção de órgãos à distância, para transplantes cardíacos.

\section{DR. FRAGOMENI \\ (Encerrando)}

Quero agradecer aos Drs. Noedir e Figueroa, pelos comentários, que valorizaram nosso trabalho. Quanto às perguntas feitas, posso informar o seguinte: o estado hemodinâmico dos receptores do coraçāo transplantado e a evolução pós-operatória (100 pacientes) eram os seguintes: cinco pacientes estavam com suporte mecânico (sem óbitos); 30 encontravam-se na U.T.I., com administração de drogas inotrópicas (houve um óbito); 11 permaneciam em ambiente hospitalar (ocorreu um óbito) e 54 estavam no domicilio (três óbitos). Quanto à pergunta sobre a que atribuímos índices cardíacos tão elevados no pós-operatório imediato, a observação criteriosa dos quesitos para aceitação dos doadores tem participação importante nesses bons resultados. Tamém fazem parte desta estratégia uma proteção miocárdica adequada e um manejo clínico criterioso com os inotrópicos no pós-operatório imediato. Era o que eu tinha a dizer. Muito obrigado. 